\title{
Salt sorption on regenerated cellulosic fibers: electrokinetic measurements
}

\author{
Avinash P. Manian $\mathbb{D} \cdot$ Adisak Jaturapiree $\cdot$ Thomas Bechtold $\mathbb{C}$
}

Received: 6 March 2018/Accepted: 29 April 2018/Published online: 3 May 2018

(C) The Author(s) 2018

\begin{abstract}
Streaming potential measurements were conducted on lyocell and viscose fibers, to determine the relative order in sorption extents of salt cations and anions. The sorption of $\mathrm{K}^{+}$was greater than $\mathrm{Na}^{+}$ions, and the sorption extents of the anions, $\mathrm{Cl}^{-}$and $\mathrm{Br}^{-}$, were similar. Previously, we had examined accessibility of the same ions in the fibers, and found them to follow the order: $\mathrm{K}^{+}<\mathrm{Na}^{+}$and $\mathrm{Cl}^{-}<\mathrm{Br}^{-}$. From these two contrasting results, we find that the mode of salt interaction with cellulose, from aqueous solutions, changes with the salt concentration. At low concentrations, the interaction is governed by ion-exchange processes with the cellulose carboxyl groups and the Donnan equilibrium; but at higher concentrations, the interaction is a function of the mobility (or diffusivity) of the ions. Thus, sorption and accessibility of cellulose fibers as measured with salts may not apply for other solutes, and conversely, similar studies with other probe molecules may not be relevant for salts.
\end{abstract}

Keywords Lyocell $\cdot$ Viscose $\cdot$ Salt sorption · Accessibility

A. P. Manian $(\square) \cdot$ T. Bechtold

Research Institute of Textile Chemistry/Physics, University of Innsbruck, Hoechsterstrasse 73, 6850 Dornbirn, Austria

e-mail: avinash.manian@uibk.ac.at

\section{A. Jaturapiree}

Faculty of Industrial Technology, Phranakorn Rajabhat University, Bangkok 10220, Thailand

\section{Introduction}

The accessibility of fibers to reagents and catalysts influences the uniformity and extent of chemical reactions, in treatments intended to improve their performance. Nearly all textile treatments of cellulosic fibers are performed with aqueous solutions, and cellulose swells in water. Thus, it becomes useful to measure fiber accessibility in aqueous media, where the effect of fiber swelling is accounted for; rather than in non-swelling media, such as for example when accessibility is determined by vapor or gas sorption. With this in mind, we previously investigated the accessibility of two regenerated cellulosic fibers, viscose (CV) and lyocell (CLY), by measuring the sorption of salts from aqueous solutions of salt-alkali mixtures. Salts were chosen as probe molecules since they do not exhibit chemical affinity for the polymer, and alkalis were added because fiber treatments are often performed in alkaline solutions, and the alkalinity influences fiber swelling.

Both CV and CLY are composed of cellulose, and derived from wood pulp through dissolution and reprecipitation (coagulation). In the viscose process, the pulp is first derivatized to sodium cellulose xanthate, dissolved in $\mathrm{NaOH}$, and then re-precipitated in an acid solution. In the lyocell process, the pulp is directly dissolved in $\mathrm{N}$-methylmorpholine $\mathrm{N}$-oxide (NMMO), and re-precipitated in a water bath (Woodings 2001). Generally, CV fibers have a lower degree of 
polymerization, lower degree of crystallinity, higher swelling degree in water, and exhibit higher moisture regain as compared to CLY fibers (Bredereck and Hermanutz 2005).

In the previous work, $0.5 \mathrm{~g}$ fiber specimens were immersed in $50 \mathrm{ml}$ solutions of the following combinations: $\mathrm{NaOH}$ with $\mathrm{NaCl}$ or $\mathrm{NaBr}$, and $\mathrm{KOH}$ with $\mathrm{KCl}$ or $\mathrm{KBr}$ (Jaturapiree et al. 2006). The salt concentrations were always $0.02 \mathrm{~mol} / \mathrm{l}$, and the alkali concentration ranged from 0 to $8 \mathrm{~mol} / \mathrm{l}$. There were no differences of salt accessibility between the fibers. However, in both fibers, there were differences of accessibility between the salts. Regardless of the alkali content in solutions, the salt accessibility increased in the order: $\mathrm{KCl}<\mathrm{NaCl}<\mathrm{KBr}<\mathrm{NaBr}$; i.e. the $\mathrm{Br}^{-}$ salts exhibited greater accessibility than the corresponding $\mathrm{Cl}^{-}$salts, and the $\mathrm{Na}^{+}$salts exhibited greater accessibility as compared to the corresponding $\mathrm{K}^{+}$ salts.

Among the ions that were studied, the charge density increases in the order: $\mathrm{Br}^{-}<\mathrm{Cl}^{-}$, and $\mathrm{K}^{+}<\mathrm{Na}^{+}$. Cellulosic fibers develop a negative surface charge in aqueous solutions (Stana-Kleinschek et al. 2002; Trotman 1984), and electrostatic forces will influence fiber-salt interactions. As the strength of such forces is proportional to the charge densities on the ions, it was concluded that the observed results could be explained by the greater attraction between the negatively charged cellulose and $\mathrm{Na}^{+}$as compared to $\mathrm{K}^{+}$, and a greater repulsion of the $\mathrm{Cl}^{-}$as compared to $\mathrm{Br}^{-}$. The order also suggested that the salt accessibility was dictated more by the repulsion of anions than attraction of the cations. We explored these findings further with electrokinetic measurements, and the results are presented here.

\section{Materials and methods}

\section{Materials}

Two fibers were used in this investigation: lyocell (CLY) and viscose (CV), both of $38 \mathrm{~mm}$ length and 1.3 dtex linear density. They were kindly donated by Lenzing AG, Austria, and used as supplied. The salts and alkalis were of analytical grade and purchased from Sigma-Aldrich; and deionized water was used in the preparation of solutions.
Textile fibers do not exhibit a uniform diameter along their length. But a nominal diameter may be estimated from their linear density (dtex $=$ mass in $\mathrm{g}$ per $10,000 \mathrm{~m}$ length), the density of cellulose $(1.5 \mathrm{~g} /$ cc) (Hearle 2001), and with the geometric formula for the volume of a right circular cylinder $\left(\pi r^{2} L\right.$, where $r$ is the radius and $L$, the length or height). In this manner, the diameter of the fibers is estimated to be ca. $10.5 \mu \mathrm{m}$.

\section{Methods}

The streaming solutions were aqueous solutions of salt-salt and salt-alkali mixtures as shown in Table 1 . The salt-salt mixtures contained either a common cation or a common anion. The total salt concentration was always $1 \times 10^{-3} \mathrm{~mol} / \mathrm{l}$, but the mole fraction of each salt varied between 0 to 1 . The salt-alkali mixtures contained a common cation at $1 \times 10^{-3} \mathrm{~mol} /$ 1 , but the mole fraction of salt and alkali varied between 0 to 1 . Separate solutions were prepared for each combination of mole fractions, and fresh fibers were used with each solution.

There is a reduction of zeta potential magnitudes with increase in ionic strength of the streaming solutions (Delgado et al. 2005; Mikhailov et al. 2017). It is because of an acceleration in the decay of potential as function of distance from the solid surface, which is also referred to as a decrease in thickness or suppression of the electrical double layer. Hence, to promote sensitivity in measurements, the amount of electrolyte in streaming solutions is kept low $\left(10^{-4}\right.$ to $10^{-3} \mathrm{~mol} / \mathrm{l}$ electrolyte). To avoid any influence of changing ionic strengths on the results, it was decided to maintain the concentration of cations and anions at the same level in all mixtures (i.e. $\left.1 \times 10^{-3} \mathrm{~mol} / \mathrm{l}\right)$, but to vary relative proportions of the components.

The streaming potentials were measured on an electrokinetic Analyzer from Anton Paar $\mathrm{GmbH}$, Austria. The measurements were performed on a $2.50 \mathrm{~g}$ fiber plug packed in a volume of $31 \mathrm{~cm}^{3}$, in a cylindrical measurement cell with platinum electrodes. The fibers were previously soaked for $12-14 \mathrm{~h}$ in the streaming solution. During measurements, the solution was streamed along both left-toright and right-to-left directions with flow pressures of $15-40 \mathrm{kPa}$ (150-400 mbar). The asymmetric 
Table 1 The salt-salt and salt-alkali mixtures in streaming solutions

\begin{tabular}{|c|c|c|}
\hline Mixture & Components & Notes \\
\hline \multirow[t]{4}{*}{ Salt-Salt } & $\mathrm{KCl}+\mathrm{KBr}$ & \multirow{2}{*}{$\begin{array}{l}\text { Mixtures with a common cation } \\
\text { Total salt concentration }=1 \times 10^{-3} \mathrm{~mol} / 1\end{array}$} \\
\hline & $\mathrm{NaCl}+\mathrm{NaBr}$ & \\
\hline & $\mathrm{NaCl}+\mathrm{KCl}$ & \multirow{2}{*}{$\begin{array}{l}\text { Mixtures with a common anion } \\
\text { Total salt concentration }=1 \times 10^{-3} \mathrm{~mol} / 1\end{array}$} \\
\hline & $\mathrm{NaBr}+\mathrm{KBr}$ & \\
\hline \multirow[t]{4}{*}{ Salt-Alkali } & $\mathrm{KCl}+\mathrm{KOH}$ & \multirow{2}{*}{$\begin{array}{l}\text { Common cation }=\mathrm{K}^{+} \\
\text {Total cation concentration }=1 \times 10^{-3} \mathrm{~mol} / 1\end{array}$} \\
\hline & $\mathrm{KBr}+\mathrm{KOH}$ & \\
\hline & $\mathrm{NaCl}+\mathrm{NaOH}$ & \multirow{2}{*}{$\begin{array}{l}\text { Common cation }=\mathrm{Na}^{+} \\
\text {Total cation concentration }=1 \times 10^{-3} \mathrm{~mol} / 1\end{array}$} \\
\hline & $\mathrm{NaBr}+\mathrm{NaOH}$ & \\
\hline
\end{tabular}

potential in all measurements was in the range of $\pm 3 \mathrm{mV}$. At the end, the cell with fiber plug was flushed with $0.1 \mathrm{~mol} / 1 \mathrm{KCl}$, and the electrical resistance of the fiber plug and the solution conductance were re-measured.

The apparent zeta potentials were calculated from the streaming potentials with the Helmholtz-Smoluchowski equation (Eq. 1). The Fairbrother-Mastin method was applied to more accurately estimate the length and cross-sectional area of the fiber plug (Eq. 2) (Delgado et al. 2005; Jacobasch et al. 1985).

$\zeta_{\text {app }}=\frac{d U}{d p} \times \frac{\eta}{\varepsilon \times \varepsilon_{0}} \times \kappa_{L}$

$\zeta_{\text {corr }}=\frac{d U}{d p} \times \frac{\eta}{\varepsilon \times \varepsilon_{0}} \times \frac{R_{S}^{C} \times \kappa_{L}^{C}}{R_{s}}$

where $\zeta_{\text {app }}=$ apparent zeta potential $(\mathrm{V}), \zeta_{\text {corr }}=$ zeta potential corrected with more accurate estimate fiber plug length and cross-sectional area $(\mathrm{V}), d U / d p=$ slope of change in streaming potential with flow pressure $(\mathrm{V} / \mathrm{Pa}), \eta=$ streaming solution viscosity (Pa.s), $\varepsilon=$ dielectric constant of the streaming solution, $\varepsilon_{O}=$ permittivity of free space $(\mathrm{F} / \mathrm{m}), \kappa_{L}=$ bulk conductivity of streaming solution $(\mathrm{S} / \mathrm{m}), R_{S}=$ electrical resistance of fiber plug flushed with streaming solution $(\Omega), R_{S}^{C}=$ electrical resistance of fiber plug flushed with $0.1 \mathrm{~mol} / 1 \mathrm{KCl}(\Omega), K_{L}^{C}=$ bulk conductivity of $0.1 \mathrm{~mol} / \mathrm{l} \mathrm{KCl}(\mathrm{S} / \mathrm{m})$.
The zeta potential plots show the average of four repetitive determinations per fiber plug, and the error bars show the standard deviation. All comparisons were assessed with Analysis of Variance (ANOVA) and Bonferroni tests at a 0.05 level of significance, with SPSS $^{\circledR}$ (IBM Software, USA).

\section{Results}

Zeta potential

Figures 1 and 2 show the apparent zeta potentials $\left(\zeta_{\text {app }}\right)$, and the same values corrected for fiber plug dimensions $\left(\zeta_{\text {corr }}\right)$. Negative values were obtained in all measurements, and in the discussions that follow, we refer only to their magnitudes.

The results with mixtures of $\mathrm{KCl}+\mathrm{KBr}$ and $\mathrm{NaCl}+\mathrm{NaBr}$ are shown in Fig. 1a, b. The magnitudes of $\zeta_{\text {app }}$ and $\zeta_{\text {corr }}$ with $\mathrm{K}^{+}$salts were generally lower than the corresponding values with $\mathrm{Na}^{+}$salts, and the differences persisted regardless of the relative proportions of $\mathrm{Cl}^{-}$and $\mathrm{Br}^{-}$in the mixtures. The results with the mixtures of $\mathrm{NaCl}+\mathrm{KCl}$ and $\mathrm{NaBr}+\mathrm{KBr}$ are shown in Fig. 1c, d. Generally, the $\zeta_{\text {app }}$ and $\zeta_{\text {corr }}$ values with $\mathrm{Br}^{-}$were similar to the corresponding values with $\mathrm{Cl}^{-}$salts, and the similarities persisted regardless of the relative proportions of $\mathrm{K}^{+}$and $\mathrm{Na}^{+}$in the mixtures. In all results shown in Fig. 1, the $\zeta_{\text {app }}$ 
Fig. 1 The zeta potentials of the fibers with salt-salt mixtures. In parts $\mathbf{a}, \mathbf{b}$, the values are plotted against mole fractions of bromide salts in the mixtures; and in parts $\mathbf{c}, \mathbf{d}$, the values are plotted against mole fractions of the potassium salts in mixtures. The gray symbols show the apparent values $\left(\zeta_{\text {app }}\right)$, and the white symbols show the values after the Fairbrother-Mastin correction $\left(\zeta_{\text {corr }}\right)$

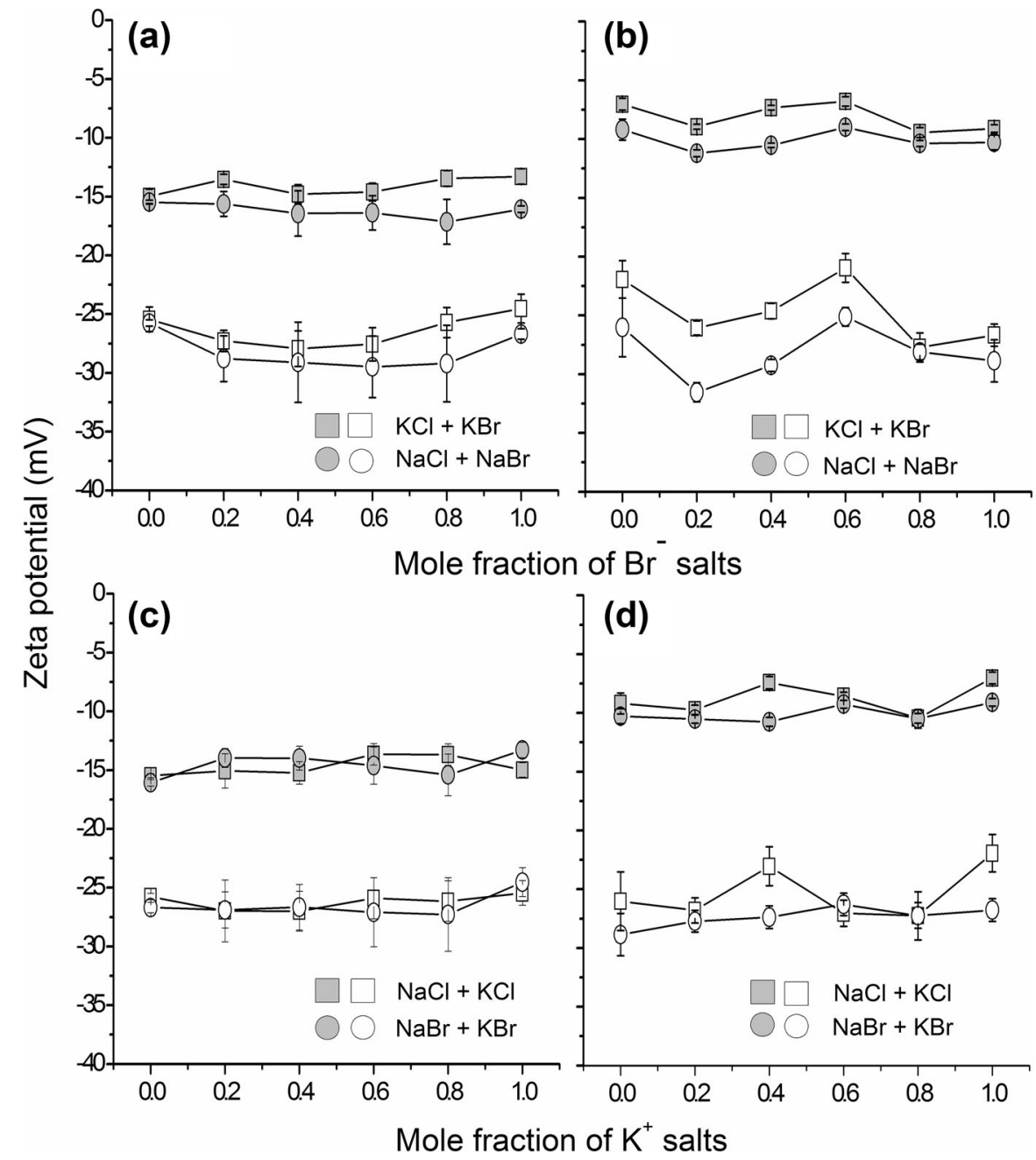

magnitudes of CV were lower than CLY, but the $\zeta_{\text {corr }}$ magnitudes of both fibers were similar.

The results with mixtures of $\mathrm{KCl}$ and $\mathrm{KBr}$ with $\mathrm{KOH}$, and of $\mathrm{NaCl}$ and $\mathrm{NaBr}$ with $\mathrm{NaOH}$, are shown in Fig. 2a, b. The zeta potential magnitudes increased with rising mole fraction of alkali in the mixtures, but in all cases, the magnitudes with $\mathrm{Cl}^{-}$containing mixtures were similar to those with $\mathrm{Br}^{-}$containing mixtures. As above, for the most part, the $\zeta_{a p p}$ magnitudes of CV were lower than CLY, but the $\zeta_{\text {corr }}$ magnitudes of both fibers were similar.

Fiber surface conductance

A rigorous determination of surface conductance in substrates is possible only for simple and regular packing geometries and this is not the case when plugs of randomly oriented fibers are packed in measurement cells. A pragmatic alternative is to determine the conductivity of the streaming solution within the fiber plug (Lyklema 1995; Briggs 1928). This is done by determining the cell constant of the plug when it is flushed with the solution of concentrated electrolyte (in our case $0.1 \mathrm{~mol} / \mathrm{KCl}$ ), and then using the value to determine plug conductivity during the regular measurements (i.e. with the salt-salt and salt-alkali mixtures). When the bulk conductivity of the streaming solution is subtracted from the plug conductivity determined in this manner, we obtain the conductivity of the streaming solution within the fiber plug $\left(K_{S}\right)$. The results are plotted in Fig. 3.

The $K_{S}$ was generally higher with the mixtures of $\mathrm{K}^{+}$salts as compared to the $\mathrm{Na}^{+}$salts (Fig. 3a), while the values with $\mathrm{Cl}^{-}$and $\mathrm{Br}^{-}$salts were generally 
Fig. 2 The zeta potentials of the fibers with salt-alkali mixtures. In parts $\mathbf{a}, \mathbf{b}$, the values are plotted against mole fractions of potassium hydroxide in the mixtures; and in parts $\mathbf{c}, \mathbf{d}$, the values are plotted against mole fractions of sodium hydroxide in the mixtures. The gray symbols show the apparent values $\left(\zeta_{\text {app }}\right)$, and the white symbols show the values after the FairbrotherMastin correction $\left(\zeta_{\text {corr }}\right)$

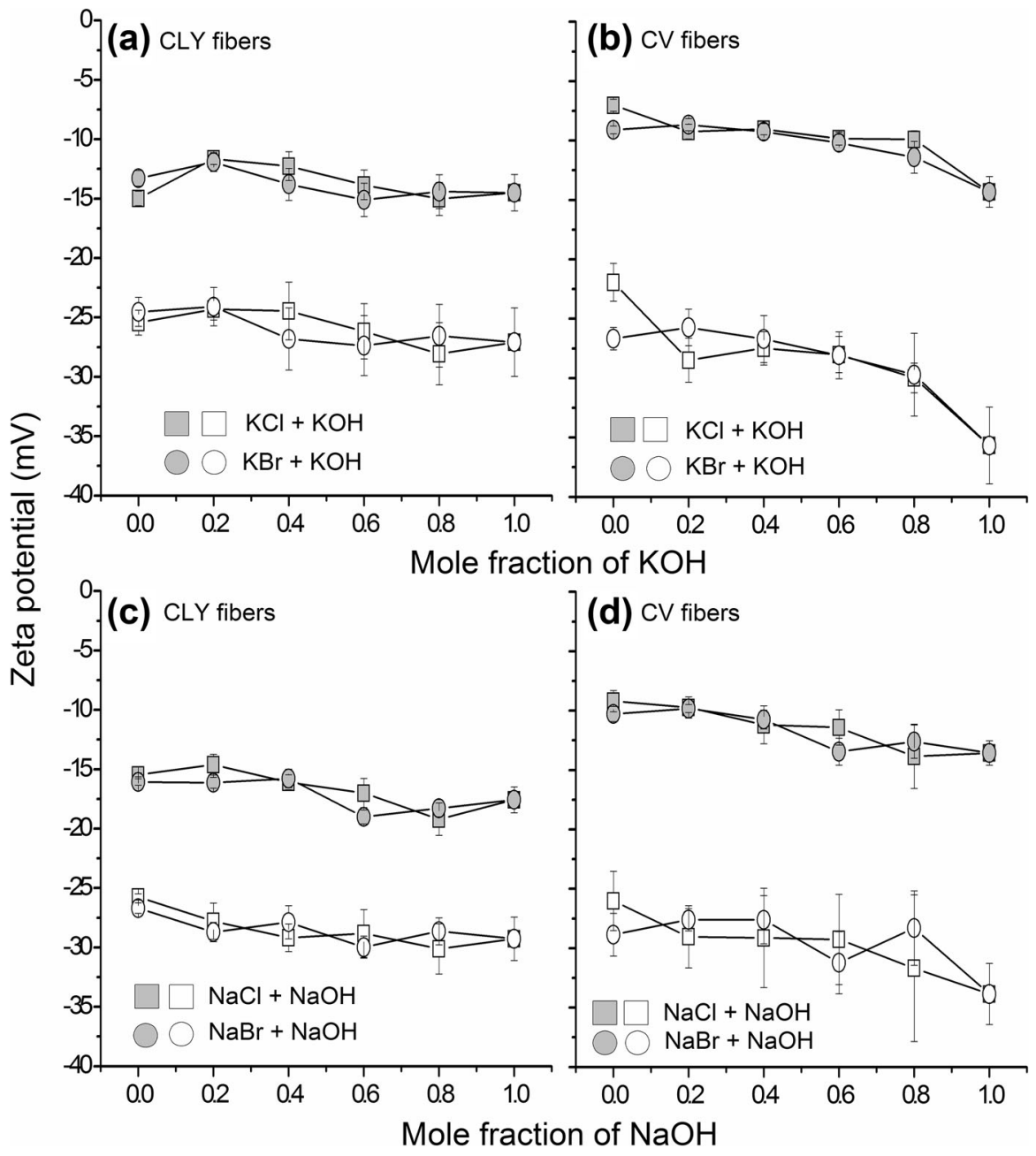

similar (Fig. 3b). In the salt-alkali mixtures (Fig. 3c, d), the $K_{S}$ did not vary significantly with change in the proportion of salt versus alkali, but the values were generally higher with $\mathrm{KOH}$-salt mixtures as compared to the $\mathrm{NaOH}$-salt mixtures. In all measurements, the $K_{S}$ with CV fibers were higher than with the CLY fibers.

\section{Discussion}

The negative zeta potentials are attributed to the dissociation of carboxyl and hydroxyl functional groups present on the cellulosic fibers, and thus the zeta potential magnitudes vary with the degree of functional group dissociation, and with the degree of sorption of ionic species (Pothan et al. 2002; Ribitsch et al. 1996, 2001; Stana-Kleinschek et al. 2001; StanaKleinschek and Ribitsch 1998). The sorption of counter-ions reduces zeta potential magnitudes and the sorption of co-ions increases them.

The literature reported $p K a$ of cellulosic carboxyl and hydroxyl groups are in the regions of 3-4 and 9-10 respectively (Farrar and Neale 1952; Räsänen et al. 2001; Bygrave and Englezos 1998; Saric and Schofield 1946; Bagrovskaya et al. 2002; Shet and Yabani 1982; Fras et al. 2004). The $\mathrm{pH}$ of all salt-salt streaming solutions was in the range of 5-6. Thus, in the measurements, it is expected that all available cellulosic carboxyl groups were fully dissociated and there was not a significant dissociation of the hydroxyl groups. Therefore, the zeta potential magnitudes did not change with the concentration of any individual salt in the mixtures. In the salt-alkali streaming 
Fig. 3 The conductivity of streaming solutions within the fiber plugs $\left(K_{S}\right)$. The values for CLY fibers are shown by the gray symbols, and the values for $\mathrm{CV}$ fibers by the white symbols

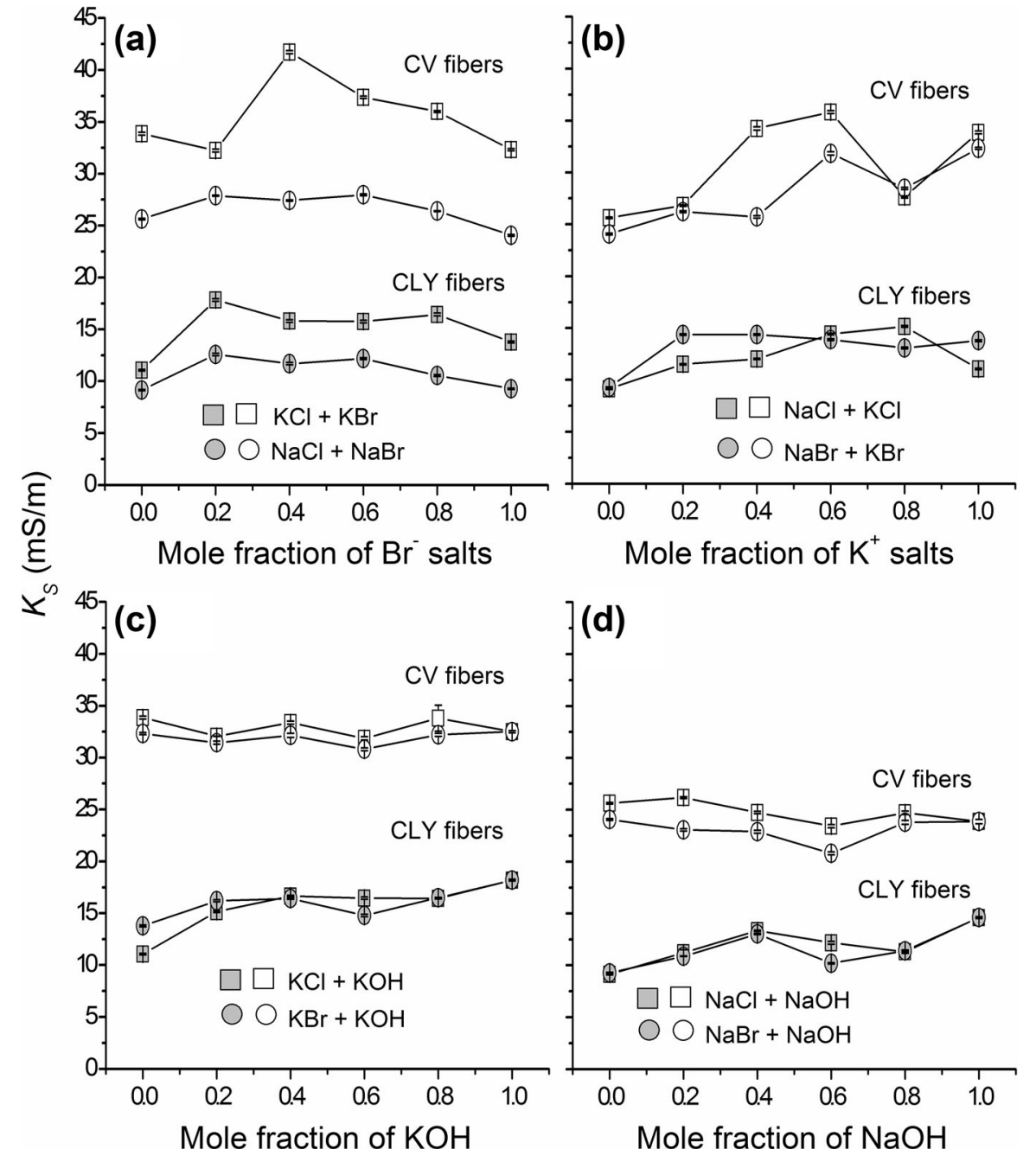

solutions, the $\mathrm{pH}$ varied changed from 5 to 11 with rising proportion of the alkali. Thus, in addition to the carboxyl group dissociation, it is expected that the degree of hydroxyl group dissociation became significant, and it continued to rise with increase in the proportion of alkali. There will also be sorption of $\mathrm{OH}^{-}$ions. Therefore, the zeta potential magnitudes increased with rise in the alkali proportion of mixtures.

The lower zeta potential magnitudes obtained with the $\mathrm{K}^{+}$as compared to $\mathrm{Na}^{+}$salt mixtures indicates that the sorption of $\mathrm{K}^{+}$ions was greater. This is opposite to the results of our previous study (Jaturapiree et al. 2006), where the $\mathrm{Na}^{+}$ions exhibited greater accessibility than $\mathrm{K}^{+}$ions. We had concluded that salt accessibility in cellulose is governed by electrostatic repulsion and attraction, but that is not tenable in light of the zeta potential results. In membrane separation processes with cellulose-related polymers such as cellulose acetate that are relatively uncharged, it is found that at low salt concentrations, the interaction with salts first proceed through cation exchange with ionized groups (e.g. carboxyl groups), and is governed by the Donnan equilibrium. But when the salt amount exceeds the available ionized groups and all charges are neutralized, the salt uptake is directly correlated with the mobility (or diffusivity) of the ions-which follows the order: $\mathrm{Na}^{+}>\mathrm{K}^{+}$and $\mathrm{Br}^{-}>\mathrm{Cl}^{-}$(Geise et al. 2014; Ohya et al. 2001a, b). This was the order of accessibility in our previous work (Jaturapiree et al. 2006), where the salt ion content in the $50 \mathrm{ml}$ solutions (1 mol) was far in excess of carboxyl groups in the $0.5 \mathrm{~g}$ of fiber specimens $(7-9 \mu \mathrm{mol})$. 
The results from electrokinetic measurements reflect the ion-exchange propensities of the salt cations. The greater selectivity in ion-exchange reactions for $\mathrm{K}^{+}$as compared to $\mathrm{Na}^{+}$, is attributed to the greater polarizing power of $\mathrm{K}^{+}$ions, which stems from its smaller radius of hydration and weaker energy of hydration (Heymann and McKillop 1941; Braithwaite and Smith 1999). Ehrlich et al. (Ehrlich et al. 1989), suggest that the greater sorption of $\mathrm{K}^{+}$on cellulose is due to selective sorption at crown-ether like arrangements of carbonyl groups. The lack of difference between the zeta potential magnitudes with $\mathrm{Cl}^{-}$and $\mathrm{Br}^{-}$salts indicates that both anions exhibited similar sorption extents. The anions are not expected to exhibit significant ion-exchange interactions with the negatively charged cellulose, and it appears that their sorption levels were limited to the amounts required to maintain charge neutrality.

The $K_{S}$ was always higher with $\mathrm{CV}$ as compared to CLY, and that may be attributed to the greater carboxyl content of the CV (Rabinov and Heymann 1943; Fras et al. 2004). As a result, almost always, the $\zeta_{\text {app }}$ magnitudes of CV were lower than those of CLY, but their $\zeta_{c o r r}$ magnitudes were similar. Lower $\zeta_{a p p}$ magnitudes of $\mathrm{CV}$ as compared to CLY have been attributed to a greater swelling of the CV (Ribitsch et al. 2001). However, we observed significant differences of $K_{S}$ between the two fiber types, which precludes comparisons of the $\zeta_{a p p}$. The similarity of $\zeta_{\text {corr }}$ magnitudes between the two fiber types indicates there were no differences in their interactions with the salt and alkali ions.

A greater sorption of an ion implies that the ion is present in larger amounts in the electrical double layer at the fiber surface, and thus a larger $K_{S}$ is expected. That was observed in our measurements with both fiber types: the $K_{S}$ was greater with the $\mathrm{K}^{+}$salts as compared to the $\mathrm{Na}^{+}$salts.

\section{Conclusions}

The results of this and our previous work (Jaturapiree et al. 2006), suggest that the mode of salt sorption and accessibility in cellulose fibers from aqueous changes with the salt concentration. At low concentrations, the salt sorption occurs through ion-exchange, and thus the relative affinities of the cations are dictated by their polarizing powers. The anion sorption extents are limited only to the extents required to maintain charge neutrality of the cellulose. At higher salt concentrations, i.e. when the salt amount exceeds that of available carboxyl groups and all charges are neutralized, the salt accessibility in cellulose is dictated by the mobility or diffusivity of both the cations and anions, which in turn are inversely proportional to their hydration sizes. Thus, the fiber accessibility as measured with salts may not apply for other solutes, and conversely, accessibility studies with other probe molecules may not be relevant for salts. As pointed out by a reviewer, it will be of interest to conduct similar studies with salts containing multivalent ions (e.g. $\mathrm{Mg}^{2+}, \mathrm{Al}^{3+}, \mathrm{SO}_{4}{ }^{2-}, \mathrm{PO}_{4}{ }^{3-}$, etc.).

The presence of carboxyl groups on cellulose fibers increase the ion concentration at and around the fiber surface and significantly increase the conductivity within the fiber plug, and may lead to an underestimation of the zeta potential. Thus, in streaming potential measurements, it may be more prudent to calculate the zeta potentials with a correction term for the length and cross-sectional area of the fiber plugs.

Acknowledgments Open access funding provided by University of Innsbruck and Medical University of Innsbruck. The authors gratefully acknowledge the donation of cellulosic fibers by Lenzing AG, Austria.

Open Access This article is distributed under the terms of the Creative Commons Attribution 4.0 International License (http:// creativecommons.org/licenses/by/4.0/), which permits unrestricted use, distribution, and reproduction in any medium, provided you give appropriate credit to the original author(s) and the source, provide a link to the Creative Commons license, and indicate if changes were made.

\section{References}

Bagrovskaya NA, Nikiforova TE, Kozlov VA (2002) Influence of solvent acidity on equilibrium sorption of $\mathrm{Zn}$ (II) and Cd(II) by cellulose-based polymers. Russ J Gen Chem 72(3):345-348

Braithwaite A, Smith JF (1999) Chromatographic methods, 5th edn. Kluwer, Dordrecht

Bredereck K, Hermanutz F (2005) Man-made cellulosics. Rev Prog Color Relat Top 35(1):59-75

Briggs DR (1928) The determination of the \{potential on cellulose-A method. J Phys Chem 32(5):641-675

Bygrave G, Englezos P (1998) Fibre charge from potentiometric titration of kraft pulp and Donnan equilibrium theory. Nord Pulp Pap Res J 13(3):220-224 
Delgado AV, González-Caballero F, Hunter RJ, Koopal LK, Lyklema J (2005) Measurement and interpretation of electrokinetic phenomena (IUPAC technical report). Pure Appl Chem 77(10):1753-1805

Ehrlich JI, Hunter KE, Fullerton GD, Cameron IL (1989) Selective sorption of potassium over sodium: an X-ray microanalysis study of processed cotton fibers. Physiol Chem Phys Med NMR 21(2):177-183

Farrar J, Neale SM (1952) The distribution of ions between cellulose and solutions of electrolyte. J Colloid Sci 7(2):186-195

Fras L, Laine J, Stenius P, Stana-Kleinschek K, Ribitsch V, Dolecek V (2004) Determination of dissociable groups in natural and regenerated cellulose fibers by different titration methods. J Appl Polym Sci 92(5):3186-3194

Geise GM, Paul DR, Freeman BD (2014) Fundamental water and salt transport properties of polymeric materials. Prog Polym Sci 39(1):1-42. https://doi.org/10.1016/j. progpolymsci.2013.07.001

Hearle JWS (2001) Physical structure and fiber properties. In: Woodings C (ed) Regenerated cellulose fibres. Woodhead Publishing, Cambridge, pp 199-234. https://doi.org/10. 1533/9781855737587.199

Heymann E, McKillop GC (1941) Studies on the lyotropic series. III. The adsorption of salts on cellulose. J Phys Chem 45(2): 195-203

Jacobasch H-J, Bauböck G, Schurz J (1985) Problems and results of zeta-potential measurements on fibers. Colloid Polym Sci 263(1):3-24

Jaturapiree A, Manian AP, Bechtold T (2006) Sorption studies on regenerated cellulosic fibers in salt-alkali mixtures. Cellulose 13(6):647-654. https://doi.org/10.1007/s10570006-9069-9

Lyklema J (1995) Electrokinetics and related phenomena. In: Lyklema $\mathbf{J}$ (ed) Fundamentals of interface and colloid science. Volume II: solid-liquid interfaces, vol 2. Academic, San Diego. https://doi.org/10.1016/S18745679(06)80007-3

Mikhailov VI, Torlopov MA, Martakov IS, Krivoshapkin PV (2017) Stability of nanocrystalline cellulose in aqueous $\mathrm{KCl}$ solutions. Colloid J 79(2):226-233. https://doi.org/10. 1134/s1061933x17020065

Ohya H, Semenova SI, Fujimoto T, Ogihara J, Fukaya S, Mori K, Aihara M, Negishi Y (2001a) Effect of electro-chemical properties of chloride salts on their diffusional parameters in symmetrical cellulose acetate membranes. Desalination 141(3):301-314
Ohya H, Semenova SI, Sawada A, Fukaya S, Suzuki Y, Aihara M, Negishi Y (2001b) Effect of electro-chemical properties of sodium salts of various anions on their diffusional parameters in symmetrical cellulose acetate membranes. Desalination 140(3):235-245

Pothan LA, Bellman C, Kailas L, Thomas S (2002) Influence of chemical treatments on the electrokinetic properties of cellulose fibres. J Adhes Sci Technol 16(2):157-178

Rabinov G, Heymann E (1943) Electrokinetic properties and surface conductivity of cellulose and oxycellulose, with reference to the carboxyl-group content. J Phys Chem 47(9):655-668

Räsänen E, Stenius P, Tervola P (2001) Model describing Donnan equilibrium, $\mathrm{pH}$ and complexation equilibria in fibre suspensions. Nord Pulp Pap Res J 16(2):130-139

Ribitsch V, Stana-Kleinschek K, Jeler S (1996) The influence of classical and enzymatic treatment on the surface charge of cellulose fibres. Colloid Polym Sci 274(4):388-394

Ribitsch V, Stana-Kleinschek K, Kreze T, Strnad S (2001) The significance of surface charge and structure on the accessibility of cellulose fibres. Macromol Mater Eng 286(10):648-654

Saric SP, Schofield RK (1946) The dissociation constants of the carboxyl and hydroxyl groups in some insoluble and solforming polysaccharides. Proc $\mathrm{R}$ Soc Lond A 185(1003):431-447

Shet RT, Yabani AM (1982) Polyelectrolyte behavior of chemically modified cotton cellulose. J Appl Polym Sci 27(2):631-636

Stana-Kleinschek K, Ribitsch V (1998) Electrokinetic properties of processed cellulose fibers. Colloids Surf A 140(1):127-138. https://doi.org/10.1016/S09277757(97)00301-4

Stana-Kleinschek K, Kreze T, Ribitsch V, Strnad S (2001) Reactivity and electrokinetical properties of different types of regenerated cellulose fibres. Colloids Surf A 195(1-3):275-284

Stana-Kleinschek K, Ribitsch V, Kreze T, Fras L (2002) Determination of the adsorption character of cellulose fibres using surface tension and surface charge. Mater Res Innov 6(1):13-18. https://doi.org/10.1007/s10019-0020168-4

Trotman ER (1984) Dyeing and chemical technology of textile fibres, 6th edn. Charles Griffin \& Company Ltd., London

Woodings C (2001) A brief history of regenerated cellulosic fibres. In: Woodings C (ed) Regenerated cellulose fibres. Woodhead Publishing Limited, Cambridge, pp 1-21 